\title{
José Carlos Ulloa Abad (Catá) Homenaje transcurrido en el Hospital Clínico de Santiago
}

Veo a José Carlos Ulloa Abad, como un hombre entrañable sin dobleces, nada visceral, aparentemente sencillo, buen conversador y por lo tanto no fácil de conocer en profundidad. Un hombre familiar no solo en su casa, con sus hijos, su mujer (Aurea), sino además con sus amigos entre los que se encuentran los médicos los que también han sido sus clientes.

Mi primer contacto con José Carlos ocurrió unos meses antes de la inauguración de la entonces Residencia Juan Canalejo a principios del año 1972, en una reunión de la Sociedad Gallega de Patología Digestiva que había organizado el cirujano Dr Montoto, y que tuvo lugar en la Cámara de Comercio en La Coruña. Yo asistí porque tenía el deseo personal de escuchar y saludar al que fuera mi maestro el Profesor José Perianes, que pronunció una conferencia sobre hepatitis.

José Carlos estaba allí, yo no lo sabia, lo supe después, el fue quien llevó a buen término la organización de la reunión, él era el artesano. Menciono esta reunión porque desde entonces él ha estado detrás de muchos encuentros médicos. Él era y es el hombre, a veces oculto, el hombre imprescindible que acabó, a fuerza de estar ahí, por salir a la luz y pasar a primera fila.

Creo que por vocación siguió la actividad de representaciones comerciales heredada quizás de su padre, centrándose en productos sanitarios y farmacéuticos. A finales de los años 60 se hizo cargo de la gerencia de laboratorios Lácer para toda Galicia que después fue extensiva también a
Asturias y otras provincias del noroeste. Su despacho estuvo en un principio en su propio domicilio hasta que en el año 1974 se inauguró el local de laboratorios Lácer en la plaza de Orense de La Coruña. Allí siempre fuimos bien muy bien recibidos, una delegación donde se impartieron cursos, conferencias y sesiones clínicas. Creo que, para un médico, la sesión clínica es la forma más íntima de la formación continuada, porque durante la misma se ve reflejado el médico, ante el caso que se discute. Las sesiones eran al principio semanales, se fueron distanciando a medida que en el entonces hospital "Juan Canalejo" (actual CHUAC), se fueron formalizando las actividades docentes, aunque continuaron los cursos, conferencias y siguió siendo un lugar de encuentro y de trabajo.

Bajo mi punto de vista hay una serie de hitos en la vida de José Carlos, que quiero resaltar, aunque por descartado para él quizás otras vivencias han sido tanto o más importantes.

En primer lugar quiero hacer mención de su colaboración con la medicina y con la medicina interna en particular. Ella comenzó de forma regular en el año 1970, en la organización del IX congreso de la Sociedad Española de Medicina Interna en Santiago, reunión presidida por el profesor Oya, y cuyo tema estrella fue la obesidad.

En relación con la Sociedad Gallega de Medicina Interna (SOGAMI) se hizo cargo de la secretaria a los dos años de su fundación, a raíz de su tercer congreso celebrado en Lugo en 1986, una reunión presidida por Albino Pérez Carnero. Un congreso memorable pues fue no solo exitoso bajo el punto

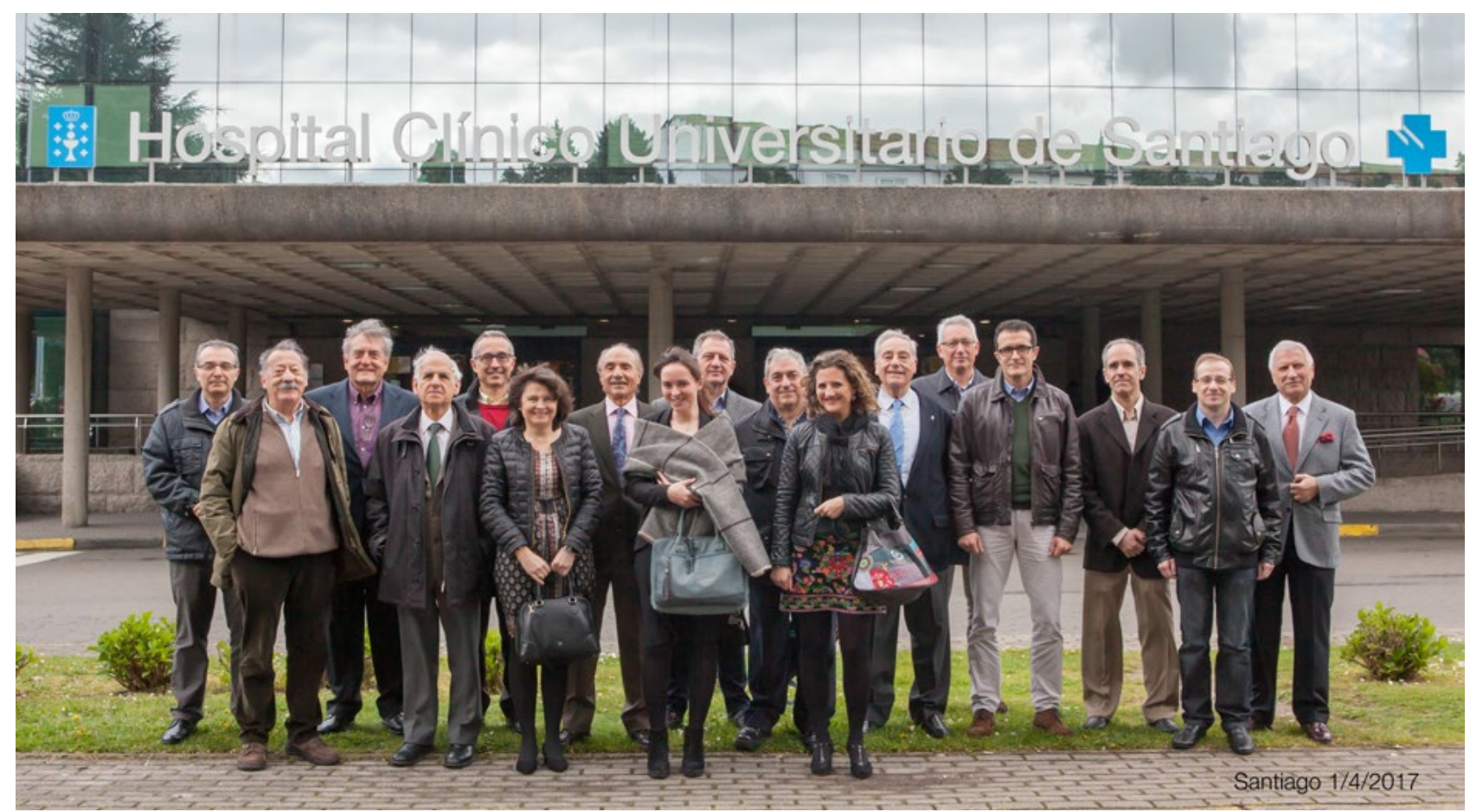


de vista científico sino que también en sentido económico, gracias a al buen hacer de Albino, y que tuvo como consecuencia que durante varios años "los papeles de Albino" así Ios llamaban en la secretaría, se utilizaron para la correspondencia de la SOGAMI durante varios años.

La capacidad gerencial de José Carlos le llevó a colaborar y organizar numerosos congresos nacionales y regionales, destacando congresos de traumatología, cardiología, neumología, hipertensión arterial, pediatría y SIDA entre otros. Ha formado un fructífero tandem con Berta Cuña jefa del servicio de farmacia del Hospital Juan Canalejo, organizando sucesivos cursos sobre antibioterapia, cuyo interés traspasó el área local. Su mérito además destaca por haber hecho todo este trabajo a mayores y en cierto modo al margen de la empresa donde siempre ha trabajado.

Ostentó la Secretaría Técnica y organizativa de las siguientes sociedades:

- Sociedad Gallega de Patología Digestiva (1972/1979)

- Sociedad Gallega de Pediatría (1971/1972)

- Sociedad Gallega de Cirugía Ortopédica y Traumatología. SOGACOT (1981/2001)

- Asociación Galega de Medicina Familiar y Comunitaria, (1982/1986)

- Asociación Asturiana de Medicina Familiar y Comunitaria (1983/1986)

- Asociación Cántabra de Medicina Familiar y Comunitaria (1984/1985)

- Sociedad Gallega de Medicina Interna, SOGAMI (1985/2017)

- Sociedad Gallega de Cardiología, SOGACAR (1983/2001)

- Sociedad Gallega Interdisciplinaria del Sida, SOGAISIDA (1998/2017)

Un segundo aspecto que quiero resaltar es su relación con el Dr Luis Gutiérrez Moyano y la revista Galicia Clínica.

La revista Galicia Clínica ha tenido tres períodos, el primero desde su implantación a finales de los años 20 por el padre de Dr Gutiérrez Moyano hasta el año 1985 cuando José Domingo Pedreira Andrade y Alfonso Castro Beiras la relanzaron. Una revista distribuida a todos los médicos de Galicia, a la que en las décadas de los 70 y 80 ya no se le prestaba suficiente atención pero que seguía teniendo para algunos la importancia de su trayectoria, de su historia; había sido un nexo de unión de la clase médica gallega desde las Jornadas Médicas Gallegas celebradas a finales de los años 20 y principios de los años 30. Una revista injustamente olvidada. Me acuerdo de haber leído algunos artículos durante mis estudios, uno especialmente me quedó grabado, la conferencia inaugural de la Facultad de Medicina delcurso 1957-58 dictada por don Ulpiano Villanueva sobre los virus, en aquella época un tema de actualidad por el entonces reciente descubrimiento de la doble hélice por Watson y Crick (1952).

El tercer período y actual de la revista como órgano de la SOGAMI comenzó en el año 2008 decisión que se tomó en una reunión con ocasión del congreso Nacional de Medicina Interna y XXV aniversario de la SOGAMI.

José Carlos ha sido el factotum de la revista no solo él sino toda la plantilla de Lácer, incluso su propia esposa Ita (Aurita) que le ayudaba a enviar los correos a los socios de la SOGAMI.

La historia de Galicia Clínica me recuerda también la de la Revista Clínica Española de andadura parecida pero a nivel español, ya que su prestigio fue languideciendo hasta acabar siendo recogida por la Sociedad Española de Medicina Interna como órgano oficial. Los internistas siempre hemos estado al rescate de valores históricos de la medicina.

Pero el aspecto más importante que quiero destacar de José Carlos es su propia personalidad.

Es difícil para un comercial ser prudente; ante el dinero y el negocio la prudencia estorba, pero hay algo que la robustece, la profesionalidad. La profesionalidad no es una virtud en si misma sino un complejo de virtudes, sobre todo dos: la responsabilidad en el trabajo, en la empresa, y la vocación, es decir el amor a la profesión. Responsabilidad de estar realmente convencido de que uno esta haciendo algo útil y serio en la sociedad. Amor a la profesión, saber ser fiel al producto, a la empresa y a la clientela. Vender un producto con convencimiento de que es realmente algo importante. Creo que por todo esto José Carlos habría sido también un buen médico.

José Carlos Ulloa es parte de la historia de la medicina de la Coruña desde mediado el siglo XX hasta el momento actual, un período que ha sido llamado por los filósofos la época post moderna, manteniendo siempre una honestidad vital envidiable en una época de relativismo ético. Estos años han sido tiempos de grandes avances farmacológicos. Creo que José Carlos ha tenido cierta envidia de lo que ha sido llamado el Farmacólogo clínico

Su colaboración con los médicos siempre lo hizo al margen de la promoción de sus productos, lo hacía por voluntad de servicio sin dejar de ser fiel a su empresa a la que por otra parte su propia actitud desinteresada ha revertido en su éxito como delegado comercial.

Es socio de honor de la SOGAMI desde el año 2006. Nombramiento que tuvo lugar en un acto entrañable en el CírcuIo de Artesanos en Lugo con ocasión del XXIII congreso de nuestra sociedad. Este acto de hoy en el Hospital Clínico de Santiago no hace sino reafirmar este nombramiento. 